\title{
Simulator Fungsi Dummy Load Menggunakan Kontrol Komputerise
}

\author{
Teguh Budi Prayogo
}

PUSDIKLAT, UPDL Makassar

teguhbudiprayogo@pln.co.id

teguhbudiprayogo@yahoo.com

\begin{abstract}
Dummy Load is used as an imitation load on the loading practice on a PLTD or PLTS generator. The existing dummy load currently installed is the conventional resistive dummy load type which is dominant at active power. The problem is that the dummy load does not yet represent the actual load condition, namely the RLC load. The power consumption by the dummy load is controlled by varying the firing angle ' $\alpha$ ' of the thyristor-pair Therefore it is necessary to improve the function of the dummy load by improving and developing the design and construction. The design of the construction improvement and development will be carried out on the main components and the digital computerized monitoring and control system for its operation. In this paper, the microcontrollerbased electronic load controller (ELC) as a voltage and frequency stabilizer is designed when the dummy load is operated. This tool can prevent damage due to the frequency and output voltage of the distribution system. The result of the reconstruction is to make the PLTD / PLTS dummy load that has the ability of dummy load RLC balanced load / unbalanced load for operating loading practices, wherein operation it uses a digital computerized control system that can program manually / auto and has a facility/feature event recorder.
\end{abstract}

Keywords: Dummy Load, RLC, Function Enhancement, Computer Control System

\begin{abstract}
ABSTRAK
Dummy Load digunakan sebagai beban tiruan pada pratikum pembebanan pada pembangkit PLTD atau PLTS. Dummy load existing yang terpasang sekarang adalah jenis dummy load resistif konvensional yang dominan pada daya aktif. Masalah yang ada adalah dummy load tersebut belum mewakili kondisi beban yang sebenarnya secara keseluruhan yaitu beban RLC. Oleh sebab itu perlu dilakukan peningkatan fungsi pada dummy load tersebut dengan memperbaiki dan mengembangkan desain dan konstruksinya. Desain perbaikan dan pengembangan konstruksi akan dilakukan pada komponen utama dan sistem monitoring dan kontrol digital komputerise untuk pengoperasiannya. Dalam makalah ini diuraikan tentang perancangan electronic load controller (ELC) berbasis mikrokontroler sebagai stabilizer tegangan dan frekuensi saat dummy load dioperasikan. Alat ini dapat mencegah kerusakan akibat frekuensi dan tegangan keluaran dari sistem distribusi Hasil dari rekonstruksi adalah menjadikan dummy load PLTD / PLTS yang mempunyai kemampuan dummy load RLC beban seimbang / beban tidak seimbang untuk praktik pembebanan operasi, dimana dalam pengoperasiannya memakai sistem kontrol digital komputerise yang dapat diprogram manual/auto dan mempunyai fasilitas/feature event recorder.
\end{abstract}

Kata Kunci: Dummy Load, RLC, Peningkatan Fungsi, Sistem Kontrol Komputerise 


\section{PENDAHULUAN}

Penggunaan Dummy Load untuk praktikum pembebanan pada PLTD atau PLTS sangat diperlukan karena selain sudah ditetapkan pada kurikulum dan silabus pembelajaran, praktikum tersebut diperlukan oleh siswa dalam menerapkan teori yang sudah dipelajari pada kondisi operasional yang sebenarnya, dan dapat memberi siswa pengalaman operasional teknis guna meningkatkan pengetahuan,pemahaman dan keterampilan siswa terhadap karakteristik beban RLC pada operasi seimbang dan tidak seimbang pada sistem tenaga listrik.

Kondisi pengoperasian pada kondisi beban seimbang dan tidak seimbang beban RLC sangat mempengaruhi efesiensi operasi sistem tenaga listrik yang mengaitkan efesiensi pada sistem pembangkit, transmisi dan distribusi yang secara keseluruhan meliputi faktor - faktor yang mempengaruhi konsumsi bahan bakar, susut teknis transmisi dan susut teknis distribusi yang tentu saja sangat berpengaruh terhadap biaya operasional sistem yang menjadi komponen utama yang mempengaruhi BPP (Biaya Pokok Produksi).

Saat ini sistem monitoring indikator yang dipakai untuk mengetahui karakteristik dan keseimbangan beban di end structure yang mempunyai otoritas organisasi, otoritas manajemen dan otoritas teknis yang terpisah adalah masih individual dan semi intergrated dalam satu sistem. Dimana sistem monitoring indikator beban terintegrasi hanya dimiliki oleh Load Control Center (APD dan $\mathrm{RCC})$

Pada tulisan ini, juga menggunakan acuan pada penelitian yang dilakukan sebelumnya di Gunung Sawur 1 MHPP yang berlokasi di Desa Sumberwuluh, Kecamatan Candipuro, Kabupaten Lumajang, Jawa Timur, Indonesia pada ketinggian $650 \mathrm{~m}$ di atas permukaan laut. Penelitian dimulai Februari hingga Mei 2018. Peralatan yang digunakan adalah Fluke 1735 tiga fase power logger yang digunakan untuk merekam data listrik pada beban dummy di Gunung Sawur 1 MHPP. Dimana investigasi energi muatan dummy di Gunung Sawur 1 MHPP menggunakan langkah-langkah berikut:

1. Persiapan power logger.

2. Pemasangan sensor probe dan klem.

3. Rekaman forevery 1 menit.

4. Merekam data logger selama beberapa hari.

5. Perekaman terhenti.

6. Pelepasan Probe dan klem.

7. Mengunduh data yang direkam.

8. Pengolahan data

Adalah suatu misprestasi apabila pegawai PLN yang terkait dengan dengan tugas tugas pengoperasian sistem tenaga listrik apabila tidak memahami karakteristik beban RLC dalam kondisi seimbang atau tidak seimbang pada operasional sistem tenaga listrik yang dapat menimbulkan beban anggaran operasi yang tidak seharusnya dikeluarkan. Oleh sebab itu rekonstruksi desain akan dilakukan pada dummy load laboratorium PLTD /PLTS khususnya di PLN UPDL Makassar diharapkan dapat meningkatkan knowledge dan skill siswa dalam memahami pengoperasian sistem tenaga listrik yang berdampak pada efisiensi pengoperasian 


\section{METODOLOGI}

Desain dan spesifikasi dasar dummy load existing:

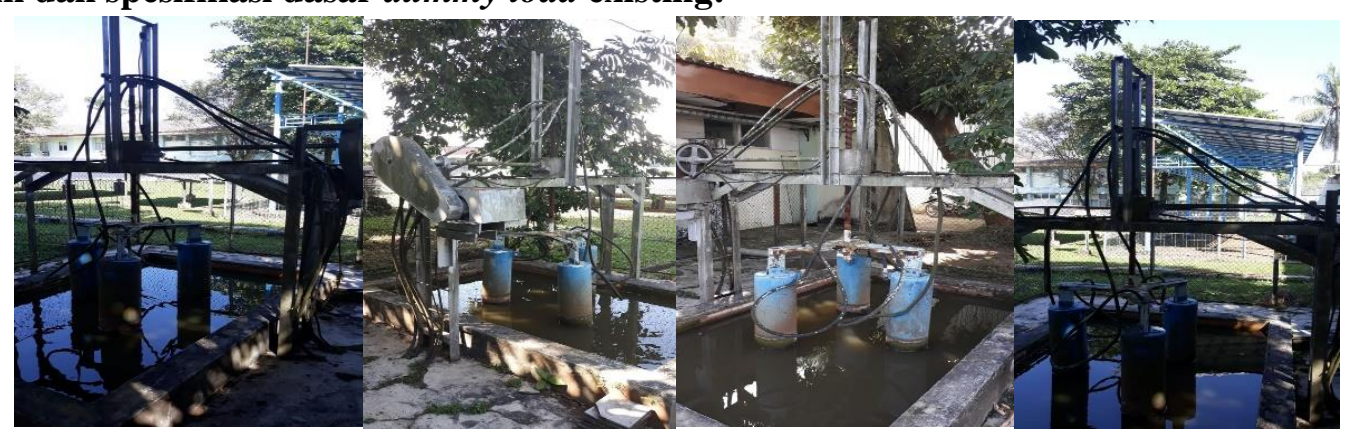

Gambar 1. Dummy Load Existing

Spesifikasi Dummy Load existing bekerja pada sistem 3 phasa dengan median material dummy berupa campuran plat besi dengan beton dan Liquid Air Garam, dengan Tegangan / Arus Kerja / Daya: 400/250 VAC / 1250 Ampere / max $500 \mathrm{KW}$, memakai sistem pengoperasian manual dengan kontrol motor Raise / Down, pembuatan / dibangun sendiri +/- pada tahun 1985.

Desain dan spesifikasi pengembangan optimalisasi fungsi dummy load:

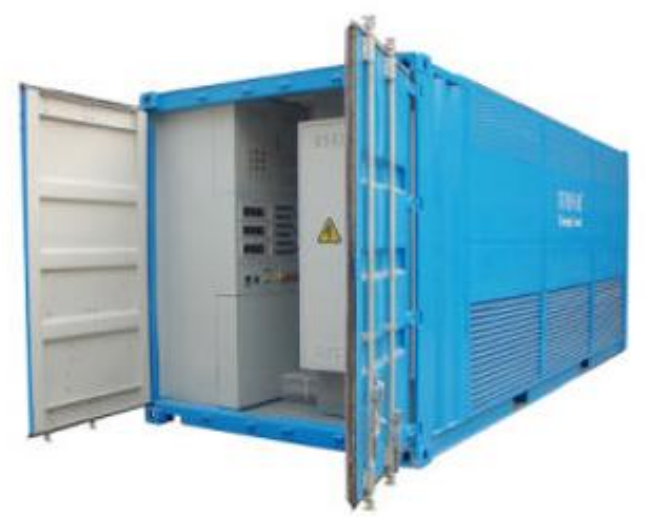

Gambar 2. Dummy Load (Unit Utama dan Unit control komputerisenya) dengan peningkatan fungsi feature sesuai kebutuhan.

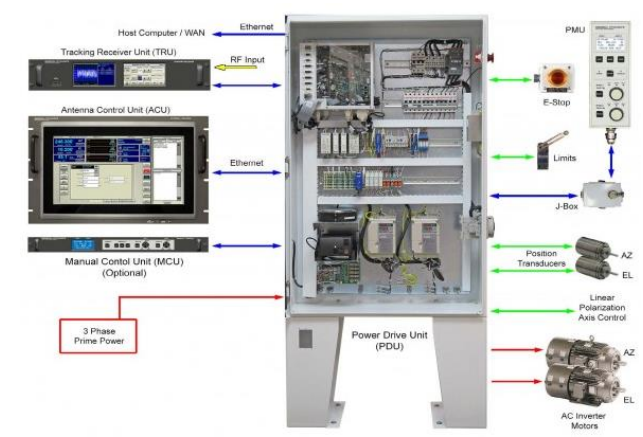

Gambar 3. Spesifikasi Dummy Load yang bekerja pada sistem 3 phasa

Spesifikasi: Mempunyai tipe Variable Resistif/Induktif/Capasitif Dummy Load yang bekerja pada sistem 3 phasa memakai median material campuran plat besi dengan beton dan Liquid Air Garam, Induktor dan Kapasitor dengan Tegangan / Arus Kerja / Daya: 400/250 VAC / 1250 Ampere / max 
$500 \mathrm{KW}$ dengan sistem pengoperasian programable berbasis komputer, rencana dibuat / dibangun sendiri di PLN UPDL Makassar tahun 2020.

Sistem elektrik kontrol komputerised / ELC menggunakan PSCAD (Power System CAD) adalah graphical user interface yang sangat baik dan fleksibel. PSCAD memungkinkan untuk membuat konstruksi sebuah rangkaian, menjalankan sebuah simulasi, analisa hasil dan manajemen data terintegrasi secara lengkap. Animasi pengontrolan dan pengukuran juga tersedia, jadi kita dapat mengubah parameter sistem, menjalankan simulasi dan melihat hasilnya secara langsung.

\section{Teori dan Pengolahan Data Pengembangan dan Peningkatan Fungsi Dummy Load:}

Proses pekerjaan menggunakan referensi control ELC (Electronic Load Controller) The ELC works on closed loop system to maintain constant speed operation of generator yang sudah dipraktekkan oleh beberapa dari beberapa jurnal antara lain sebagai berikut:

Kontroller yang dibuat oleh Rajendra Adhikari dan Rojan Bhattarai memang masih menggunakan satu jenis beban saja (Resistif) jadi masih diperlukan pengembangan untuk load berjenis kapasitif dan induktif, jadi masih memerlukan modifikasi Hard/Soft Ware saat pekerjaan konstruksinya.

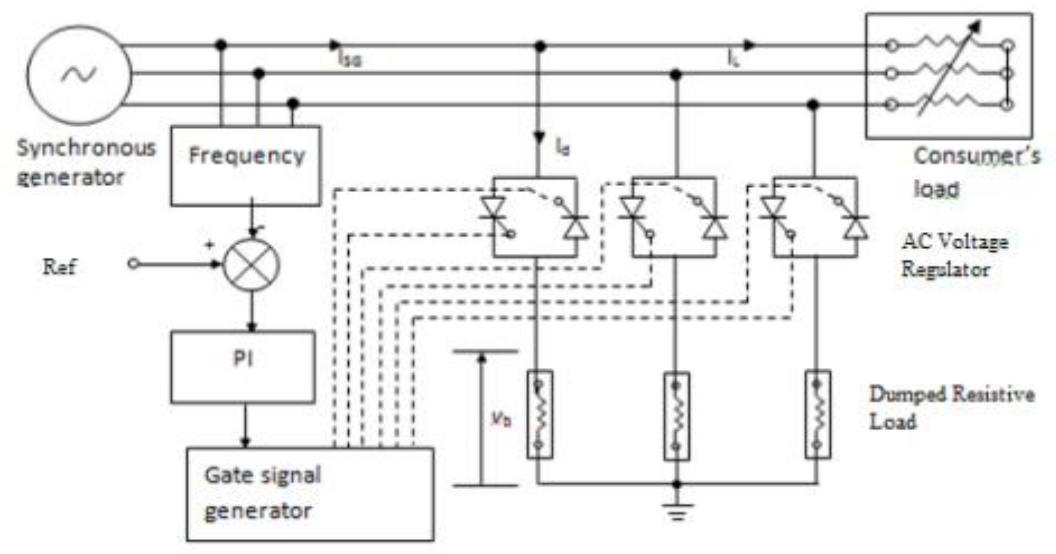

Fig 1 Detail circuit diagram of ac voltage controller based ELC

Gambar 4. Detail Circuit Kontroler Basis ELC

Berikut blok diagram desain pengolahan signal kontrol untuk drive fungsi kontribusi beban Resistif/Kapasitif dan Induktif nya yang dibuat oleh Shailendra Kumar Rai dkk Desain ELC menggunakan penyearah jembatan yang dikontrol dan chopper IGBT yang mengumpankan beban dump resistif/kapasitif/induktif yang telah diimplementasikan untuk simulasi. Konsumsi daya chopper telah bervariasi menurut siklus tugas chopper. Hasil simulasi telah menunjukkan perubahan dalam berbagai parameter, yaitu, tegangan eksitasi, arus stator, output daya mekanik, daya output generator, daya melintasi beban konsumen, dan beban dump sebagai akibat dari perubahan permintaan / beban.

Dari dua referensi diatas dijadikan sebagai desain dasar yang tentunya saat konstruksi nanti diperlukan penyempurnaan apa bila belum tertuang di perencanaannya dan apabila terjadi kelebihan daya maka dilakukan pembuangan beban melalui ELC yang terhubung di dummy load. 


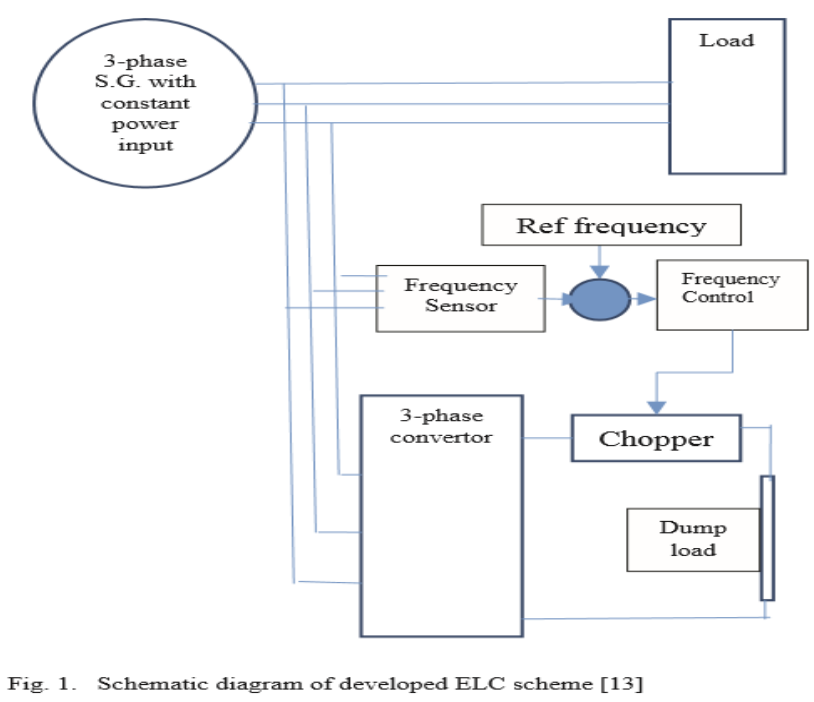

Gambar 5. Skema ELC

\section{HASIL}

Kondisi dummy load existing spesifikasinya terbatas dan pengoperasiannya manual, sedangkan dummy load hasil pengembangan spesifikasinya lebih luas dengan pengoperasian bisa manual/auto berbasis komputer yang bisa diprogam pengoperasiannya dilengkapi dengan event recorder.

Tabel 1. Perbandingan spesifikasi dummy load existing dan dummy load hasil pengembangan/rekonstruksi.

\begin{tabular}{|c|c|c|c|}
\hline \multicolumn{2}{|c|}{$\begin{array}{c}\text { COMPARING TABLE BEFORE n } \\
\text { AFTER }\end{array}$} & Dummy load Existing & $\begin{array}{c}\text { Dummy load Hasil } \\
\text { Rekonstruksi }\end{array}$ \\
\hline \multirow{3}{*}{ Tipe / Jenis Beban } & R (Resistif) & $\bigcirc$ & $\bigcirc$ \\
\cline { 2 - 4 } & L (Induktif) & & $\bigcirc$ \\
\cline { 2 - 4 } & C (Capasitif) & & $\bigcirc$ \\
\hline \multirow{3}{*}{ Mode Operasi } & Individual & & $\bigcirc$ \\
\cline { 2 - 4 } & Serempak & & $\bigcirc$ \\
\hline \multirow{3}{*}{ Model Pembebanan } & Seimbang & $\bigcirc$ & $\bigcirc$ \\
\cline { 2 - 4 } & Tidak Seimbang & & $\bigcirc$ \\
\hline \multirow{5}{*}{ Operasi dan Kontrol } & Manual & & $\bigcirc$ \\
\cline { 2 - 4 } & Servo Motor & & $\bigcirc$ \\
\cline { 2 - 4 } & Komputer & & $\bigcirc$ \\
\cline { 2 - 4 } & Programable & & $\bigcirc$ \\
\cline { 2 - 4 } & Event Recorder & & \\
\cline { 2 - 4 } & Grafik Recorder & & \\
\hline
\end{tabular}

\section{KESIMPULAN}

Hasil Pengembangan dan Optimalisasi fungsi konstruksi dan pengoperasian dummy load yang baru memberi keleluasaan spesifikasi dan pola pengoperasian variabel yang lebih luas dan dengan mudah bisa memenuhi model beban yang diinginkan sesuai kurikulum dan silabus program praktek dengan keluaran secara visual dan rekam digital pada setiap model pembebanan yang diinginkan 


\section{UCAPAN TERIMAKASIH}

Terimakasih saya ucapkan kepada semua pihak (PKK - PLN Pusdiklat; STT - PLN dan pihak lainnya yang secara langsung dan tidak langsung) membantu saya menyelesaikan Penugasan Penulisan Karya Tulis Ilmiah ini, semoga Allah SWT dapat membalasnya dengan pahala yang besar kepada bapak / ibu sekalian ... Aamiin .....

\section{DAFTAR PUSTAKA :}

[1] R. Bhattarai, R. Adhikari, dan I. Tamrakar, "Improved Electronic Load Controller for Three Phase Isolated Micro-Hydro Generator," no. October, 2013.

[2] M. H. Riaz et al., "Micro hydro power plant dummy load controller," Proc. - 2018, IEEE 1st Int. Conf. Power, Energy Smart Grid, ICPESG 2018, no. November, hal. 1-4, 2018.

[3] B. Info dan P. Description, "Hebei Kaixiang Electrical Technology Co ., Ltd . 3 Phase Load Bank 3000kw Load Bank for Generator Testing," hal. 1-6, 2019.

[4] Y. I. Nakhoda dan F. K. Rahayu, "Perbaikan Kualitas Tegangan Menggunakan Kompensasi Dynamic Voltage Restore ( Dvr ) Dan Distribution Static Compensator ( D- Statcom ) Dengan Software Pscad / Emtdc Power Simulation," no. January 2008, 2016.

[5] S. K. Rai, "Implementation of Electronic Load Controller for Control of Micro Hydro Power Plant," 2015. 